\title{
INTERNACIONALIZAÇÃO DE MICRO, PEQUENAS E MÉDIAS EMPRESAS: UMA AVALIAÇÃO SOBRE O PROCESSO DECISÓRIO ESTRATÉGICO
}

DOI: 1014211/regepe.v5i3.398

Artigo recebido em:25/07/2016 Artigo aprovado em: 12/12/2016

Roberto Marinho Figueiroa Zica - Universidade FUMEC ${ }^{1}$ Carlos Alberto Gonçalves - Universidade FUMEC/Univers. Federal de Minas Gerais-UFMG ${ }^{2}$ Henrique Cordeiro Martins - Universidade FUMEC ${ }^{3}$

Resumo: Com o aumento da competição das empresas por novos mercados e a manutenção das posições conquistadas nos nichos em que atuam, os executivos têm buscado formas de atuar em mercados ainda pouco explorados, bem como refinar modelos de gestão já utilizados, de modo a superar os desafios impostos. Em âmbito mundial, esse aceleramento da competição estimula a adoção de novas ferramentas de gestão, ações de exploitation e exploration, a flexibilização de barreiras para produtos e serviços, a customização de bens e a melhor interface com os novos mercados consumidores. Com o acesso viabilizado aos mercados internacionais, determinados tipos de empresas optam pela estratégia de expandirem suas operações a outros países, o que pode ocorrer em várias formas diferentes, podendo se constituir como a maior dimensão do processo contínuo de estratégia. Embora a internacionalização seja historicamente associada a empresas multinacionais, tendências mais recentes sugerem que o mercado internacional está cada vez mais povoado por micro, pequenas e médias empresas. A questão proeminente para este trabalho é a compreensão sobre quais razões motivam ou desmotivam os empresários de pequenos negócios a expandirem suas operações a outros países e, sobretudo, como ocorre o processo desta decisão na ação de internacionalizar seus negócios.

Palavras-chave: Processo Decisório Estratégico; Internacionalização; Micro, Pequenas e Médias Empresas.

\footnotetext{
${ }^{1}$ Endereço: E-mail: roberto.marinho@sebrae.com.br

2 E-mail: carlos@face.ufmg.br

${ }^{3}$ E-mail: henrique.martins@fumec.br
}

ZICA, R. M. F.; GONÇALVES, C. A.; MARTINS, H. C. Internacionalização de micro, pequenas e médias empresas: uma avaliação sobre o processo decisório estratégico. 


\title{
INTERNATIONALIZATION OF MICRO, SMALL AND MEDIUM-SIZED ENTERPRISES: AN EVALUATION OF STRATEGIC DECISION-MAKING PROCESS
}

\begin{abstract}
With the increase of the enterprise competition for new markets and the maintenance of the conquered positions at the areas in which they operate, the executives have been searching ways to operate in less exploited markets, as well as refine models of management that are already used, in order to overcome the imposed challenges. In a worldwide context, this competition acceleration stimulates the adoption of new managing tools, exploitation and exploration actions, barriers loosening for the products and services, goods customization and the best interface with new market's consumers. With the granted access at the international market, certain types of enterprises choose the strategy to expand its operations to other countries, which can occur in many different ways, where it can act as a major dimension of the ongoing strategy process. Although the internationalization has been associated with the multinational enterprises, mostly trends suggest that the international market has been increasingly populated by micro, small and medium enterprises. The main question for this work is the comprehension about which actions motivate or discourage the small business entrepreneurs to expand their operations to other countries and, mainly, how this decision process occurs at the action for internationalize their business.
\end{abstract}

Keywords: Strategic Decision-Making Process; Internationalization; Micro, Small and Medium Enterprises.

\section{Introdução}

Com o aumento da competição das empresas por novos mercados e a manutenção das posições conquistadas nos nichos em que atuam, os executivos têm buscado, em ritmo cada vez mais frenético, formas de atuar em mercados ainda pouco explorados (PORTER, 1996; DRUCKER, 1999; OLIVEIRA; GONÇALVES; PAULA, 2013).

Em âmbito mundial, esse aceleramento da competição estimula a adoção de novas ferramentas de gestão, a flexibilização de barreiras para produtos e serviços, a customização de bens e melhor interface com os novos mercados consumidores, contribuindo para a inclusão de novos players, como a América Latina e os países do sudeste asiático (D'AVENI; DAGNINO; SMITH, 2010).

ZICA, R. M. F.; GONÇALVES, C. A.; MARTINS, H. C. Internacionalização de micro, pequenas e médias empresas: uma avaliação sobre o processo decisório estratégico. Revista de Empreendedorismo e Gestão de Pequenas Empresas, v.5, n.3, 2016. 
A intensificação da competição em busca de novos mercados, bem como a procura por menores custos de produção contribui para uma nova geografia de determinados processos produtivos, redirecionando-os para os países semiperiféricos. Todas essas mudanças provocaram alterações na forma de produzir, administrar, distribuir e de gerir os recursos das organizações, criando novas relações entre empresas, trabalhadores e instituições, reduzindo as barreiras existentes entre os países e blocos comerciais, criando, de certo modo, homogeneidade entre essas regiões (BRITO; BRITO, 2014).

Sirmon et al. (2010) corroboram com esse pensamento de estreitamento de mercados ao ressaltarem que, em grande parte dos mercados mundiais, a tendência de homogeneização é muito latente. Este isomorfismo institucional (DIMAGGIO; POWELL, 1983) denota o aparecimento de uma estrutura e abordagem comuns entre as organizações.

Com a redução das barreiras econômicas e comerciais e uma forte tendência à adoção da ideologia de livre mercado pelos países, gerou-se maior aproximação entre mercados internacionais. Todas essas mudanças provocaram alterações na forma de produzir, administrar, distribuir e gerir os recursos das organizações, de modo a compatibilizar a organização com padrões internacionais de qualidade e produtividade (GOVINDARAJAN; GUPTA, 2001).

O fluxo de informação, capitais, pessoas e do comércio de bens e serviços são fatores que contribuem fortemente para o aumento da integração entre países e regiões. Esse fenômeno estimula a dinamicidade não apenas de questões de cunho econômico, mas também de aspectos conectados sinergicamente à cultura, tecnologia e recursos naturais (GIDDENS, 2000; CASTELLS, 2000).

De acordo com Giddens (2000), este fenômeno refere-se à intensificação das relações sociais em escala mundial, havendo incontáveis conexões entre as diferentes partes do mundo, por meio do qual os acontecimentos locais sofrem a influência dos acontecimentos verificados em outras regiões do globo. Ressalta-se que estas interconexões ocorrem nas dimensões global, local e também cotidiana, de maneira cada vez mais descentralizada. Por estarem expostas a este ambiente vívido, as empresas acabam sendo influenciadas pelas ações de mercado e de outras organizações, sendo que também exercem influência. 
Com o acesso viabilizado aos mercados internacionais, determinados tipos de empresas optam pela estratégia de expandirem suas operações a outros países. De acordo com Melin (1992), esta decisão de internacionalização configura-se como a maior dimensão do processo contínuo de estratégia.

Conforme França Filho et al. (2011), a opção pela internacionalização pode ocorrer em várias dimensões diferentes, sendo um processo ao longo de um tempo, em que a empresa desenvolve relacionamentos e operações crescentes fora de seu país de origem. Não se resume a realizar vendas fortuitas a outros países, mas sim ao desenvolvimento e mudanças de escopo de atuação da empresa, ampliação de ideias de negócios e a organização interna, (princípios, gestão, valores e convergência de normas).

Embora a internacionalização tem sido historicamente associada a empresas multinacionais, tendências recentes sugerem que o mercado internacional está cada vez mais povoado por pequenas e médias empresas (RODRIGUES; CHILD, 2012) e, em algumas situações, também por microempresas. No tocante aos pequenos negócios, as empresas tendem a primeiramente exportar para países vizinhos devido aos menores custos de transporte e a similaridade cultural (HITT; IRELAND; HOSKISSON, 2003).

Especificamente sobre o Brasil, cabe salientar que em 1988 foi deflagrado um processo de abertura da economia, após longo período de quase uma clausura econômica, baseado no sistema de preços e regras estáveis e não discriminatórias de acesso aos agentes econômicos (SILBER, 2006).

Desde aquele momento, iniciou-se um ambiente propício à competitividade mais favorável ao comércio exterior, ao aumento da produtividade e da especialização da produção. Corrobora-se a este marco, o período de estabilidade monetária que passou-se a vivenciar desde meados da década de 90 do século passado, com o lançamento e fortalecimento do Plano Real, pautando, notadamente, na tríade: controle de metas de inflação, câmbio flutuante e superávit primário.

Não obstante haver este movimento de abertura e integração com outros países, o cenário relacionado ao comércio exterior no país, especificamente para as empresas de menor porte, foco deste estudo, é bastante restritivo. Segundo 
pesquisa do Sebrae (2012), as micro e pequenas empresas (MPE) responderam por apenas $0,87 \%$ do total do valor exportado em 2011. O número de MPEs exportadoras totalizou 11.525 naquele ano, contra 11.838 em 2010, denotando redução na ordem de $2,6 \%$. Já o valor exportado cresceu $11,3 \%$, atingindo $R \$ 2,2$ bilhões em 2011. A quantidade de micro e pequenas empresas especiais (MP Especiais) somavam 1.165 no período.

Tais números servem tanto para demonstrar a atual posição das micro, pequenas e médias empresas (MPME) neste quesito, quanto para ilustrar a oportunidade de crescimento que existe. Caso a análise se concentre apenas na totalidade das exportações, por certo os pequenos negócios não possuam representatividade econômica dentro deste contexto.

Todavia, pairando o foco de atenção nos demais números que os cercam, como quantidade de empresas, empregos gerados, atuação como fornecedores e distribuidores de grandes e médias empresas, desconcentração de atividades (RUIZ; HOURNEAUX JUNIOR, 2006), é possível perceber uma perspectiva diametralmente oposta, conferindo às MPMEs, a devida relevância para a formação do Produto Interno Bruto (PIB) nacional.

Para melhor entender a dinâmica das organizações, torna-se condição sine qua non compreender como se comportam os decision-maker, genericamente, na condução estratégica de seus negócios, a forma de gestão que adotam e como a internacionalização passa a ser uma alternativa factível ao estabelecimento de uma estratégia sustentável.

Os conteúdos mais abrangentes orientam para a existência de três correntes possíveis, sendo por meio de um processo estritamente racional, calcado em dados e cálculos disponíveis, de processos ligados à intuição do empreendedor na busca por oportunidades de mercado, ou em função da network estabelecida pelo empreendedor e organização, que constroem laços relacionais que estimulam e viabilizam a realização de negócios.

Neste sentido, entende-se como relevante compreender: como ocorre o processo decisório em micro, pequenas e médias empresas, na definição estratégica que visa uma atuação internacional? 
O estudo apresenta um referencial do campo teórico atinente às principais temáticas abordadas, buscando refletir sobre determinados conceitos e apontar caminhos para a atuação no segmento e revelar como ocorre o processo de decisão de empresários na ação de internacionalizar seus negócios. O percurso teórico realizado buscará respaldar tais reflexões para posterior verificação nas pesquisas realizadas.

\section{Atuação das Micro, Pequenas e Médias Empresas no Brasil}

O universo das micro, pequenas e médias empresas no Brasil é bastante representativo, contando com mais de 6,3 milhões de empreendimentos, o que representa quase a totalidade das empresas formais, privadas e não agrícolas do país, em patamar superior a 99\% do total. Conforme apontado pelo Sebrae, somente as micro e pequenas empresas (MPE) são responsáveis por $52 \%$ dos empregos formais e $40 \%$ da massa salarial (SEBRAE, 2013). Todo este conjunto movimenta cerca de $27 \%$ do Produto Interno Bruto nacional, ano base 2011 (SEBRAE, 2014).

Mesmo com essa pujança, percebe-se que a geração e disseminação de conhecimento sobre micro, pequenas e médias empresas (MPME) vem se expandindo consideravelmente nas últimas décadas, resgatando, em alguma medida, a lacuna existente neste campo teórico. Julien (2013) corrobora essa assertiva ao afirmar que a teoria concernente sobre as micro, pequenas e médias empresas desenvolveu-se há cerca de 35 anos. O debate é relevante, pois serve para ratificar posições sobre o representativo papel que exercem as empresas de menor porte para o desenvolvimento socioeconômico e na inovação tecnológica do país, bem como evitar classificações e análises equivocadas sobre formas de atuação e impedir simplificações polissêmicas que tendem a atirá-las em "valas comuns do conhecimento".

Neste sentido, reforça a percepção de que as empresas de menor porte não devam ser compreendidas ou consideradas como um arremedo ou como incapazes de desenvolver as atividades e missão a qual se propõem. Conforme Bernardes 
(2003), as empresas de menor porte não devem ser consideradas como empresas em miniatura, já que possuem determinadas características, formas de atuação, estrutura organizacional, formação e disponibilidade de capital que as diferenciam enormemente das grandes empresas.

A conceituação de micro, pequenas e médias empresas constitui-se em um elemento de grande relevância no tocante à formulação de políticas públicas voltadas ao segmento, visando seu desenvolvimento econômico (FILION, 1991). Todavia, não existe no país uma única definição classificatória que pacifique a questão. Embora haja uma legislação própria que indique patamares financeiros de enquadramento de empresas, diversas entidades classificam as MPMEs em função de critérios próprios.

Baseando-se nas informações coletadas por Puga (2000), pode-se afirmar que os parâmetros utilizados para o enquadramento quanto ao porte das empresas estabelecidas no Brasil, estão orientados sob dois enfoques: em função do número de funcionários que possuem e pelo faturamento bruto anual auferido por essas empresas.

Existem três entidades no Brasil que classificam o porte das empresas de acordo com o critério de número de funcionários, sendo o Ministério do Trabalho e Emprego, o Instituto Brasileiro de Geografia e Estatística (IBGE) e o Serviço Brasileiro de Apoio às Micro e Pequenas Empresas (Sebrae).

O Quadro 1 a seguir apresentará esta classificação.

QUADRO 1 - CLASSIFICACÃO DO PORTE DAS EMPRESAS - POR PESSOAS OCUPADAS

\begin{tabular}{|l|l|l|}
\hline \multirow{2}{*}{\multicolumn{1}{c|}{ Porte }} & \multicolumn{1}{c|}{ Atividades Econômicas } \\
\cline { 2 - 3 } & \multicolumn{1}{c|}{ Serviços e Comércio } & \multicolumn{1}{c|}{ Indústria } \\
\hline Micro Empresa & Até 09 pessoas & Até 19 pessoas \\
\hline Pequena Empresa & De 10 a 49 pessoas & De 20 a 99 pessoas \\
\hline Média Empresa & De 50 a 99 pessoas & De 100 a 499 pessoas \\
\hline Grande Empresa & Acima de 100 pessoas & Acima de 500 pessoas \\
\hline
\end{tabular}

FONTE: Sebrae (2014).

A subdivisão por setor de atividade econômica é necessária, tendo em vista as diferenças operacionais existentes entre os setores de serviços, de comércio e da 
indústria, notadamente no que se refere à alocação de pessoas para o desempenho de suas atividades operacionais, táticas e estratégicas nas respectivas firmas.

Quanto à definição de porte de empresas por faturamento, este tipo de enquadramento está parametrizado de acordo com o faturamento bruto anual, servindo tanto para questões fiscais, quanto para o enquadramento perante às instituições financeiras e órgãos de apoio à exportação.

A Lei Complementar n.ำ123/2006, também conhecida por Lei Geral da MPE, traz a seguinte definição: microempresas são as pessoas jurídicas que auferem receita bruta anual de até $R \$ 360.000,00$ e empresas de pequeno porte aquelas que tenham receita bruta anual superior a $R \$ 360.000,00$ e até $R \$ 3.600 .000,00$.

Outra classificação relevante a ser apresentada é a do Mercosul. Conforme o Ministério do Desenvolvimento, Indústria e Comércio Exterior (MDIC, 2015), a metodologia para enquadramento das empresas em função do porte é resultante de um critério que associa o número de empregados da empresa ao valor exportado no período considerado, distribuídos por ramo de atividade.

A seguir, o Quadro 2 apresentará os parâmetros de classificação por porte.

QUADRO 2 - CLASSIFICAÇÃO DO PORTE DA EMPRESA - MERCOSUL

\begin{tabular}{ccccc}
\hline \multirow{2}{*}{ Porte } & \multicolumn{2}{c}{ Serviços e Comércio } & \multicolumn{2}{c}{ Indústria } \\
\cline { 2 - 5 } & Pessoas & Valor - US\$ & Pessoas & Valor - US\$ \\
Micro Empresa & Até 5 & Até 200 mil & Até 10 & Até 400 mil \\
Pequena Empresa & De 6 a 30 & Até 1,5 milhões & De 11 a 40 & Até 3,5 milhões \\
Média Empresa & De 31 a 80 & Até 7 milhões & De 41 a 200 & Até 20 milhões \\
Grande Empresa & Acima de 80 & $\begin{array}{c}\text { Acima de } 7 \\
\text { milhões }\end{array}$ & Acima de 200 & $\begin{array}{c}\text { Acima de 20 } \\
\text { milhões }\end{array}$ \\
\hline
\end{tabular}

FONTE: MDIC (2015)

Salienta-se que estes critérios estão de acordo com os parâmetros adotados no Mercosul, conforme disposto nas Resoluções Mercosul-GMC n 90/93 e 59/98. 
Internacionalização de Micro, Pequenas e Médias Empresas

De acordo com Oliveira, Nunes e Destefeni (2012), as mais proeminentes teorias do processo de internacionalização oferecem formas de compreender melhor os meios e métodos para a tomada de decisão, quando uma empresa opta por expandir sua produção em um mercado localizado em outro país.

Com o avanço tecnológico e o crescimento exponencial na quantidade de interconexões percebida após o advento e popularização da internet, bem como as demais tecnologias de informação e comunicação, inaugurou-se fecundo solo para que um grande número de empreendedores de pequenos negócios passassem a ter acesso a informações, antes quase inacessíveis, bem como a possibilidade de prospectar outros mercados (OECD, 2004).

Conforme Giddens (2000), o grande fluxo de informação, capitais, pessoas e do comércio de bens e serviços são fatores que contribuem para o aumento da integração entre países e regiões, instigando a dinamicidade econômica, cultural e tecnologia.

Neste contexto, algumas empresas, de diversos portes, percebem a estratégia de expandirem suas operações a outros países como uma alternativa factível. De acordo com Melin (1992), a internacionalização constitui-se como a mais relevante dimensão do processo contínuo de estratégia, não se resumindo a realizar vendas fortuitas a outros países, mas sim ao desenvolvimento e mudanças de escopo de atuação da empresa, ampliação de ideias de negócios e a organização interna (princípios, gestão, valores e convergência de normas).

Deve-se salientar, contudo, que na literatura existem duas correntes principais sobre a internacionalização: o "enfoque econômico", precedida de análises macroeconômicas, e o "enfoque organizacional", que coloca o homem organizacional no lugar do econômico (PAIVA JUNIOR; GUERRA, 2009).

De acordo com Hilal e Hemais (2003), durante a década de 1970, pesquisadores da Universidade sueca de Uppsala (JOHANSON; WIEDERSHEIMPAUL, 1974; JOHANSON; VAHLNE, 1977, 1990) mostraram interesse no processo de internacionalização das empresas suecas, desenvolvendo um modelo de como 
estas empresas escolhiam os mercados para se internacionalizar. O Modelo Uppsala deu origem à Escola de Negócios Nórdica e agregou novos objetos à sua linha de pesquisa, possibilitando que os estudos sobre Negócios Internacionais deixassem de ser percebidos eminentemente como fenômeno econômico, mas também serem analisados sob a perspectiva da Teoria do Comportamento Organizacional (HILAL; HEMAIS, 2003).

O Modelo de Uppsala preconiza que: (i) as empresas se internacionalizam, preferencialmente, para países considerados psiquicamente próximos ao seu país de origem; e (ii) o processo de internacionalização segue os passos incrementais de comprometimento de recursos em cada novo país.

No tocante aos pequenos negócios, de acordo com Hitt, Ireland e Hoskisson (2003), os mesmos tendem a primeiramente exportar para países vizinhos devido aos menores custos de transporte e a similaridade cultural. Todavia, no caso brasileiro, conforme será apresentado nas pesquisas realizadas, o destino das exportações das MPEs tem se orientado sistematicamente a outros países fora do cone sul.

Outro aspecto relevante a ser reforçado é que embora a internacionalização venha sendo historicamente associada a empresas multinacionais, tendências recentes sugerem que o mercado internacional está cada vez mais povoado por pequenas e médias empresas (RODRIGUES; CHILD, 2012).

De acordo com Rodrigues e Child (2012), a teoria do capital social indica que as empresas estabelecem relações entre si, formam redes de integração, geram consequências positivas e oportunidades de diferentes matizes. Tudo isso contribui para aumentar a compreensão sobre como as pequenas empresas realizam operações além de suas fronteiras. Acredita-se que o capital social possa desencadear e fomentar a internacionalização. Outra consideração que os autores realizam é que a construção de laços com grandes players pode ser relevante para reduzir determinados custos, mitigar eventuais assimetrias de informações e gerar conhecimento para lidar em ambientes internacionais. Duas fontes de capital social emergem nessas situações: as relações pessoais e o apoio institucional. 
Antes de passar à próxima seção, torna-se relevante mencionar o comportamento destas MPMEs no tocante a exportações (habitualmente o primeiro passo à internacionalização).

Segundo pesquisa do Sebrae (2012), embora as MPEs respondam por apenas $0,87 \%$ do total das exportações brasileiras, existe grande quantidade de empresas de menor porte com atividades exportadoras, totalizando 11.525 no ano de 2011, atingindo o patamar de US $\$ 2,2$ bilhões. Com relação à sua participação no total das exportações, a pesquisa identificou que as 5.058 microempresas respondem por $0,07 \%$ do volume exportado, correspondendo a US $\$ 181,2$ milhões. As pequenas empresas são responsáveis por gerar $0,80 \%$ do total do valor exportado, correspondendo a cerca de US $\$ 2$ bilhões.

Embora o valor exportado pelas MPEs tenha crescido em 2011, na ordem de $11,3 \%$, o crescimento médio percebido entre as médias e grandes empresas ficou em $29,2 \%$ e $24,7 \%$, respectivamente. Dentre a pauta de produtos exportados, os manufaturados são os predominantes pelas MPEs, tendo respondido em 2011 por $75 \%$ das vendas totais.

De acordo com o MDIC (2015), no ano de 2011 houve aumento do número de empresas de médio porte que exportaram. No referido ano, 5.710 médias empresas venderam para o mercado exterior, apresentando crescimento de 7,6\% em relação ao ano anterior. O valor comercializado foi de US\$ 8, 819 bilhões em 2011. O principal setor exportador, nesta categoria de estabelecimentos, foi o de máquinas e equipamentos mecânicos, sendo que as exportações corresponderam por $11,9 \%$ do total.

\section{Processo Decisório}

$\mathrm{O}$ ato de tomar decisões é inerente à condição humana. Escolher a opção mais factível dentre as alternativas existentes em um determinado contexto é algo bastante recorrente nos mais diversos níveis dentro das organizações, bem como a assunção dos desdobramentos decorrentes desta ação. 
Conforme afirma Nooraie (2012), o processo decisório consolida-se como uma das mais importantes funções dos gestores, em qualquer natureza de organização. Todavia, essa ação pode se tornar uma atividade bastante complexa, em função das variáveis envolvidas, da quantidade (suficiente ou não) de informações pertinentes e dos distintos impactos que esta decisão pode acarretar.

Nesse sentido, Nutt (2011) afirma que determinadas decisões tomadas pelos gestores das organizações podem repercutir de maneira bastante problemática, tanto para as organizações, quanto para as pessoas.

Para Gibcus, Vermeulen e Radulova (2008), entre as perspectivas existentes, não existe um consenso a cerca de uma definição que melhor represente o campo de estudo sobre processo decisório. Mesmo possuindo fundamentações epistemológicas distintas, percebe-se que estas perspectivas buscam, essencialmente, a compreensão sobre o comportamento do decision-maker.

Em consonância com Mintzberg, Raisinghani e Thoret (1976), o processo de decisão estratégica caracteriza-se pela inovação e por sua complexidade, no qual as organizações iniciam a análise a partir de uma visão mais generalista, buscando: (i) identificar a oportunidade; (ii) desenvolver a ideia; e (iii) selecionar as possibilidades.

De acordo com Rodrigues (1985), critérios seletivos devem ser adotados ao se analisar as teorias sobre processo decisório, tendo em vista a existência de diversas elucidações sobre como ocorre o processo da tomada de decisão. Estes conceitos vão desde o entendimento que as ações humanas são definidas pela razão, atribuindo demasiada importância à racionalidade econômica, quanto a orientação que as escolhas são desprovidas de sentido, dado a inconsistência do comportamento humano e as limitações da racionalidade humana. Há ainda um terceiro tipo, em que se enfatiza mais o processo decisório em si, do que os valores econômicos ou supostos valores organizacionais.

O processo decisório entendido por meio da racionalidade, tendo como instrumentos, determinada quantidade de informações, cálculos econômicos, dados estatísticos e um conjunto de ferramentas de análise, fundamenta-se da ideia central de que a organização, ou em última análise o empreendedor, lidando com toda a complexidade envolvida, possui as condicionantes necessárias, seleciona o melhor curso de ação para auferir a maximização de seus objetivos.

ZICA, R. M. F.; GONÇALVES, C. A.; MARTINS, H. C. Internacionalização de micro, pequenas e médias empresas: uma avaliação sobre o processo decisório estratégico. 
Em função de este modelo apresentar certo distanciamento da realidade e se posicionando contrário aos excessos deste "homem econômico", Simon (1976) apresenta seu contraponto, propondo o "homem administrativo", pois crê que nenhum decision-maker, embora frequentemente busque agir racionalmente, teria a capacidade de sistematizar e analisar todos os fatores e alternativas possíveis para a tomada de decisão. Seus estudos o levaram a postular sobre o princípio da racionalidade limitada.

Considerando esta limitação de identificação de todas as condicionantes para a melhor tomada de decisão, a constante mutação do ambiente e a própria natureza do comportamento humano, o processo decisório passa a considerar também aspectos não diretamente ligados à decisão racional, tais como: hábitos de grupos, preferências inconstantes das pessoas, fatores motivacionais e contextos organizacionais. O resultado da decisão passaria a ser não o melhor, mas tão somente aquele considerado satisfatório ou adequado (RODRIGUES, 1985 apud MARCH; SIMON, 1958).

A terceira tipologia inclui a perspectiva de poder ou interesse, na qual as decisões envolvem, além de temas relacionados à racionalidade-burocrática weberiana e os aspectos organizacionais, o aspecto político. Cyert e March (1963) admitem que uma organização pode ser entendida como uma coalizão política de múltiplos objetivos traçados, mas em permanente mutação, onde as decisões são mais o resultado de constantes negociações e barganhas do que uma ação estritamente racional.

Esse tipo de processo decisório merece especial atenção, pois mesmo sabendo que decisões estratégicas são, por definição, relativamente significativas, estas decisões de aspecto político-organizacional são fundamentais para a sobrevivência de uma organização, pois impactam além de exterioridades econômicas, determinados atributos corporativos, como a distribuição interna de recursos e a reputação (CHILD; ELBANNA; RODRIGUES, 2010).

Outro aspecto a ser considerado na tomada de decisão seria a intuição do decision-maker, que no caso de um pequeno negócio centra-se na figura do empreendedor ou socioproprietários. Percebe-se que a gestão dos pequenos negócios é espessamente marcada pelo estilo pessoal dos empreendedores e 
sócios. Assim, é compreensível que a maneira como conduzem suas atividades reflita cognitivamente no processo decisório, genericamente, das pequenas empresas (GERLETTI, 2009).

A percepção que paira é que com o aumento da competição dos mercados, a crescente entrada de novos competidores, decorrente do movimento da globalização, as rápidas mudanças tecnológicas e alteração do comportamento dos consumidores, o desafio para os tomadores de decisões estratégicas torna-se cada vez mais exigente (OLIVEIRA; GONÇALVES; PAULA, 2013).

\section{Procedimentos metodológicos}

No âmbito das ciências sociais, entende-se a pesquisa como um instrumento fundamental para a resolução de problemas coletivos (MARCONI; LAKATOS, 2002). Para a realização deste trabalho, foram realizadas pesquisas tanto de natureza quantitativa, quanto qualitativa, de modo a encontrar respostas para as questões apresentadas, bem como obter informações fidedignas para o encaminhamento de sugestões de caminhos possíveis e novos estudos.

Importante dizer que, inicialmente, o trabalho foi embasado em um amplo processo de revisão de bibliografia pertinente, análise documental de pesquisas recentemente realizadas, dados secundários e pesquisa qualitativa de campo.

No tocante à pesquisa quantitativa, o método caracteriza-se, segundo Richardson (1989), pela utilização de técnicas quantificáveis, seja na coleta de informações ou no tratamento dos dados, por meio da estatística, na qual os resultados são quantificados, registrados e sistematizados. Para a obtenção destas informações, o presente trabalho valeu-se de estudo realizado pelo Sebrae (2013), intitulado "Pesquisa de Internacionalização: micro, pequenas e médias empresas".

Foram entrevistados 245 empreendedores e dirigentes de pequenos negócios de Minas Gerais, durante o período de agosto de 2012 a março de 2013. O universo considerado pela pesquisa foi composto por micro, pequenas e médias empresas mineiras que exportavam, abrangendo o universo de 1.205 empresas. A 
amostra de 245 empresas teve um intervalo de confiança de 95\% e margem de erro máximo de $5,6 \%$.

Sobre a pesquisa qualitativa, a escolha da abordagem encontra amparo em Gil (1999), ao explicar que esse tipo de pesquisa permite um aprofundamento das questões de significado e percepções humanas, colhidas no ambiente natural e não perceptíveis nos métodos e técnicas estatísticas quantitativas. A pesquisa foi do tipo descritivo (TRIVIÑOS, 1987).

As pesquisas de campo foram realizadas durante o mês de julho e agosto de 2014, por meio de entrevistas semiestruturadas com empreendedores e dirigentes de seis empresas de pequeno ou médio porte com alguma atividade internacional. $\mathrm{O}$ objetivo desta verificação foi perceber, de maneira mais individualizada, como estes empresários procederam à decisão de exportar ou continuar internacionalizando suas atividades.

As empresas foram selecionadas aleatoriamente de um banco de dados, em função de seu porte e setor de atuação, por realizarem alguma atividade relacionada à internacionalização, possuir sede em Minas Gerais e disponibilidade para responder à pesquisa. Outra informação é que estas empresas exportadoras identificadas já haviam respondido à citada pesquisa do Sebrae (2013).

Após o contato estabelecido para explicar as razões da pesquisa, 0 questionário foi enviado por e-mail ao decision-maker da empresa, tendo sido utilizada a ferramenta de questionário do Google Docs, por oferecer um ambiente bastante amigável para o respondente. Composto por 12 perguntas objetivas, o questionário utilizou escala tipo Likert para mensurar a intensidade das medidas.

\section{Resultados Apurados}

Inicialmente, a pesquisa realizada pelo Sebrae (2013) caracterizou o Perfil dos Respondentes, o Perfil da Empresa e o Perfil do Exportador, tendo chegado aos seguintes resultados:

I - Perfil do Respondente: $80 \%$ dos entrevistados possuem graduação ou pós-graduação completa ou incompleta, demonstrando qualificação acadêmica do 
segmento. Em 67,8\% das empresas, o principal responsável (respondente da pesquisa) é do sexo masculino, com idade média e 41,3 anos.

II - Perfil da Empresa: 41,2\% das empresas têm acima de 20 anos de existência e 75,5\% estão no mercado há mais de 10 anos. Em 70,6\%, os empreendedores foram os responsáveis pela fundação do negócio, sendo que em $55,5 \%$ destas empresas existem familiares envolvidos na gestão. Outra informação importante é que $65,3 \%$ das empresas são do setor industrial, sendo que atividades relacionadas à Manufatura representam 59,2\%.

Sobre a "participação das vendas anuais nos mercados", as MPEs exportadoras possuem a seguinte composição de receitas: 29,5\% provêm de vendas externas; quase a metade das vendas, 46,3\%, é proveniente de vendas dentro do próprio Brasil (excluindo o estado onde se localizam); o restante, $24,2 \%$ são oriundas de venda dentro do estado, regionais e locais (município onde se situam).

No tocante à "motivação para exportar", a maioria dos respondentes, 46,9\%, informaram que foi em função da demanda internacional pelo produto/serviço, 40,8\% informaram que foi em função da possibilidade de expandir o mercado, 14,0\% para diversificar o mercado e $16,7 \%$ disseram que a empresa foi concebida para atender o mercado externo.

Outro dado relevante apresentado pela pesquisa é sobre a "participação dos países nas exportações das MPEs mineiras", desvendando que 19,4\% de seus produtos e serviços são exportados para os Estados Unidos, 13,5\% têm como destino a Argentina, 7,3\% a China, 5,0\% o Paraguai, 4,7\% a Itália e 4,2\% o Chile. O restante dos países é bastante pulverizado.

A "participação dos clientes nas vendas anuais" concentra-se em três segmentos de mercado, sendo Varejista e Atacadista com 46,3\%, Empresas Industriais com 27,4\% e para o Cliente (consumidor) Final representando 13,8\%. O restante também é pulverizado.

Dentro do construto Finanças, 32,2\% das empresas aumentaram suas receitas em relação ao ano de $2011,39,2 \%$ mantiveram seu patamar de faturamento e $28,6 \%$ perceberam queda no faturamento. Na questão "fontes de financiamento usadas nos últimos dois anos", as empresas alegaram que quando necessitam utilizar alguma fonte de financiamento, 38,8\% valeram-se de empréstimos bancários, 
$30,6 \%$ de crédito de fornecedores, $23,3 \%$ utilizaram reinvestimento de lucros, $20,8 \%$ de linhas específicas para exportação e 20,4\% usaram o cartão de crédito como fonte. Houve outras indicações, sendo que foram aceitas múltiplas respostas.

Quando questionados sobre os "conhecimentos e competências que precisam ser desenvolvidos na empresa", 45\% dos respondentes declararam que existe forte necessidade de aprimorem outros idiomas. No tocante à "avaliação das habilidades dos funcionários", $37 \%$ dos empresários se dizem insatisfeitos ou muito insatisfeitos com o quesito idiomas estrangeiros.

III - Perfil exportador: 42,9\% das empresas responderam que as exportações representam entre $1 \%$ e $25 \%$ de seus respectivos faturamentos, $12,2 \%$ das empresas indicaram que as exportações representam entre $26 \%$ e $50 \%$ e para $16,7 \%$ das empresas respondentes, as exportações equivalem de $76 \%$ a $100 \%$ do faturamento. 59,2\% das empresas exportam mais de 4 vezes ao ano, sendo que $73,1 \%$ exportam sem a utilização de intermediários.

Sobre a "participação das empresas na exportação", no tangente ao Valor Exportado, as microempresas (menos de 20 pessoas ocupadas e exportações/importações anuais de US\$ 120 mil) correspondem a 0,04\% do volume total, as pequenas empresas (menos de 100 pessoas ocupadas e exportações/importações anuais de até US\$1,2 milhões) correspondem a 0,4\% e as MPE Especiais (menos de 20 pessoas ocupadas e exportações/importações anuais superiores a US\$1,2 milhões) correspondem a 15,6\%. Nota-se que o enquadramento das empresas está baseado no critério adotado pela Funcex. Quando se analisa o Número de Empresas Exportadoras, as microempresas respondem por $21,3 \%$ do total, as Pequenas Empresas por 29,7\% e as Micro e Pequenas Empresas Especiais por 14,0\%.

No tocante às barreiras à exportação, a pesquisa segregou a questão em barreiras internas e externas. Os principais resultados serão demonstrados na Figura 2 deste trabalho. 
Além do perfil, foi investigada a percepção dos empresários entrevistados sobre o processo voltado à decisão de exportar ou continuar internacionalizando suas atividades, quais produtos e serviços deverão serem exportados, qual o posicionamento a ser adotado, escolha de parceiros e alianças, e se esta decisão ocorre por meio de um processo analítico bem estruturado ou estritamente pela ação intuitiva, norteada pelo senso de oportunidade.

Conforme mencionado, foram entrevistadas seis empresas exportadoras de menor porte dentro do Estado de Minas Gerais, considerando os setores de atuação da indústria, do comércio e de serviços.

Dentre os aspectos levantados na pesquisa podem-se destacar os seguintes pontos:

I - Perfil da Empresa: 50\% das empresas entrevistadas têm acima de 20 anos de existência e o restante possui atuação há pelo menos 10 anos, demonstrando consistência de atuação no mercado. Entre as empresas respondentes, apenas uma é enquadrada como pequena empresa, com faturamento de até $R$ \$ 3,6 milhões, sendo que o restante possui faturamento superior a este patamar. Dois terços destas empresas realizaram sua primeira operação internacional há mais de 10 anos, possuindo experiência na atividade.

II - Perfil decisório: Ao perguntar sobre quem decidiu a respeito da primeira operação internacional, 50\% responderam que a decisão partiu do Socioproprietário ou Presidente e 33\% disseram que a decisão foi tomada pelos membros da Diretoria.

Para a questão "quanto à decisão de internacionalizar a empresa foram adotadas quais medidas?", foram disponibilizadas 5 opções, sendo: 1) puramente por intuição; 2) por já possuir contatos no exterior; 3) ter sido a empresa especificamente criada para o mercado exterior, em função de demanda ou pedido de clientes no exterior; 4) por dificuldades no mercado; 5) por evidências percebidas nos estudos e pesquisas realizadas.

Utilizando uma escala tipo Likert, os entrevistados puderam marcar, para cada natureza de resposta, qual a intensidade de sua decisão, podendo variar de menor intensidade ou uso, para maior intensidade ou utilização. 
Pelas respostas dos decision-makers, foi possível constatar que não houve tendência a polarização nas respostas. Todavia, foi dado ênfase aos construtos contatos no exterior e possuírem demanda ou pedidos de cliente no exterior, com maior incidência de respostas de intensidade mais forte. Pode-se depreender deste fato a relevância que o relacionamento, network, possui para o segmento.

Como "meta às suas operações internacionais", a metade dos empresários entrevistados pretendem expandir suas operações no (s) país (es) em que atua. E $80 \%$ dos entrevistados intencionam iniciar novas operações em outros mercados ou países. Cabe salientar que em $67 \%$ das situações, a decisão sobre a meta é tomada pelo sócio majoritário ou presidente.

Outra questão fulcral para a pesquisa foi sobre "como ocorre o processo decisório" dentro destas empresas. Também foi utilizada a escala tipo Likert, com a possibilidade de indicar qual a intensidade desta decisão, sendo que a opção com maior peso foi o consenso entre os sócios, com $67 \%$ das ocorrências. A análise de estudos e pesquisas teve peso preponderante em $60 \%$ das situações e a intuição dos sócios correspondeu a $25 \%$ das citações. Importante ressaltar que não houve entendimento sobre a questão "a operação não é realizada" em $33 \%$ dos casos e em $50 \%$ dos casos se "reúne mais dados e pesquisas para nova avaliação".

A última questão apresentada é se "a decisão tomada foi capaz de aumentar a lucratividade da empresa". $33 \%$ dos casos afirmaram que a decisão aumentou a lucratividade acima de $31 \%$ a.a. Para $17 \%$, a lucratividade ficou entre $11 \%$ e $20 \%$ a.a..

\section{Transição entre Mercados}

No tocante ao processo decisório, percebe-se que o empreendedor, na ação de decidir sobre a internacionalização de suas atividades, possui à sua disposição três formas singulares e opostas de deliberação, sendo uma mais intuitiva, outra mais racional-burocrática e uma terceira mais voltada à rede de relacionamento. Se tal hipótese for aceita como factível, torna-se possível conceber a existência de uma unidade métrica, na qual as extremidades representam os três perfis mencionados. 
Nesta hipotética unidade métrica, em uma das extremidades estaria situado um perfil específico de empreendedor que toma suas decisões baseadas em sua percepção sobre a geração de negócios e em sua intuição de que a transação se constitui em uma oportunidade de se gerar valor. Este perfil específico de empreendedor tende a agir mais em função da identificação da oportunidade do que pelo rigorismo técnico de retornos de investimentos, taxas internas de retorno ou estimativas de payback. É possível que a decisão considere determinados cálculos e avaliações, mas, supostamente, estas análises tendem a não possuírem maiores rigores técnicos ou servirem de balizamento para a tomada de decisão.

Em outro limite da métrica, consta um perfil de empreendedor que procura amparar sua decisão no pragmatismo racional-burocrático. Ao identificar alguma oportunidade, este perfil de empreendedor tende a balizar sua decisão por meio da arregimentação de dados, classificação das informações disponíveis e estruturação de demais técnicas para a tomada de decisão. Pode-se inferir que as avaliações e procedimentos analíticos deste perfil sejam dotados de maior profundidade do que o anterior.

O terceiro limite possui um perfil de empreendedor que realiza suas decisões mais calcada em aspectos que usufruam de sua rede de relacionamento (network). Com base em contatos já realizados, contratos firmados ou um conjunto de negociações bem-sucedidas com clientes e parceiros no exterior, este empreendedor consegue estabelecer e fortalecer os elos de relacionamento que os unem, potencializando a perspectiva de gerarem novos negócios.

Importante ressaltar que é bastante plausível a existência de algumas possibilidades de variação entre os três citados perfis, transitando em perfis mais acentuados nas extremidades e mais moderado ao centro. Caso o empreendedor consiga harmonizar essas três características bastante peculiares de seu comportamento, seria possível denotar o melhor aproveitamento das potencialidades de sua decisão gerencial.

A Figura 1 a seguir demonstra na unidade métrica as três extremidades, evidenciando os perfis mencionados. 


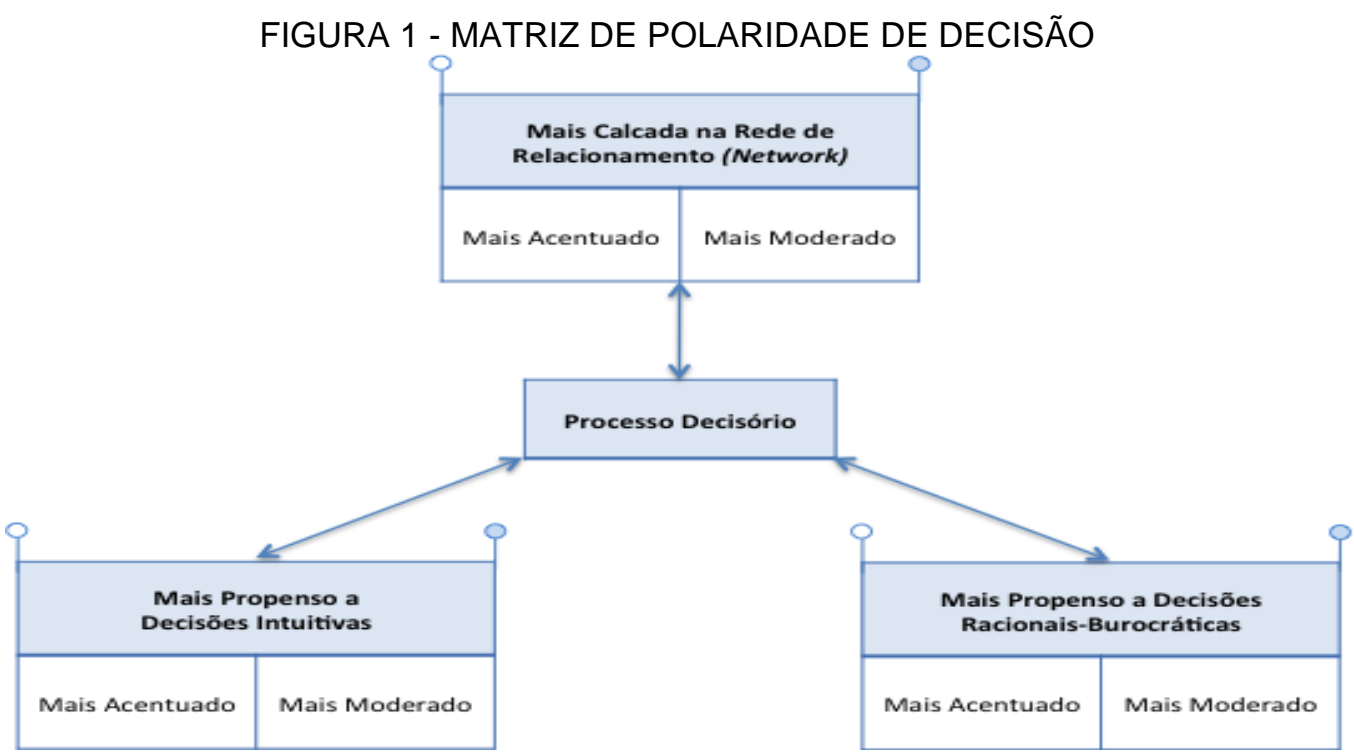

FONTE: os autores (2016).

Tomando como base o referencial teórico e sob a égide desta matriz de decisão e das pesquisas realizadas, percebe-se a existência de diversos indicativos que orientam as empresas em suas atuações, tanto no mercado interno, quanto no externo. Diante de ameaças ou oportunidades existentes no mercado e seus recursos internos, a empresa necessita decidir sobre quais caminhos deverá trilhar para obter desempenho superior e sustentável.

A Figura 2 intenciona sistematizar, por meio de dados, informações e teoria aplicada, sob quais aspectos ocorre a inclusão da perspectiva da internacionalização nas micro, pequenas e médias empresas. 
FIGURA 2 - PROCESSO DE DECISÃO NA TRANSIÇÃO ENTRE MERCADOS

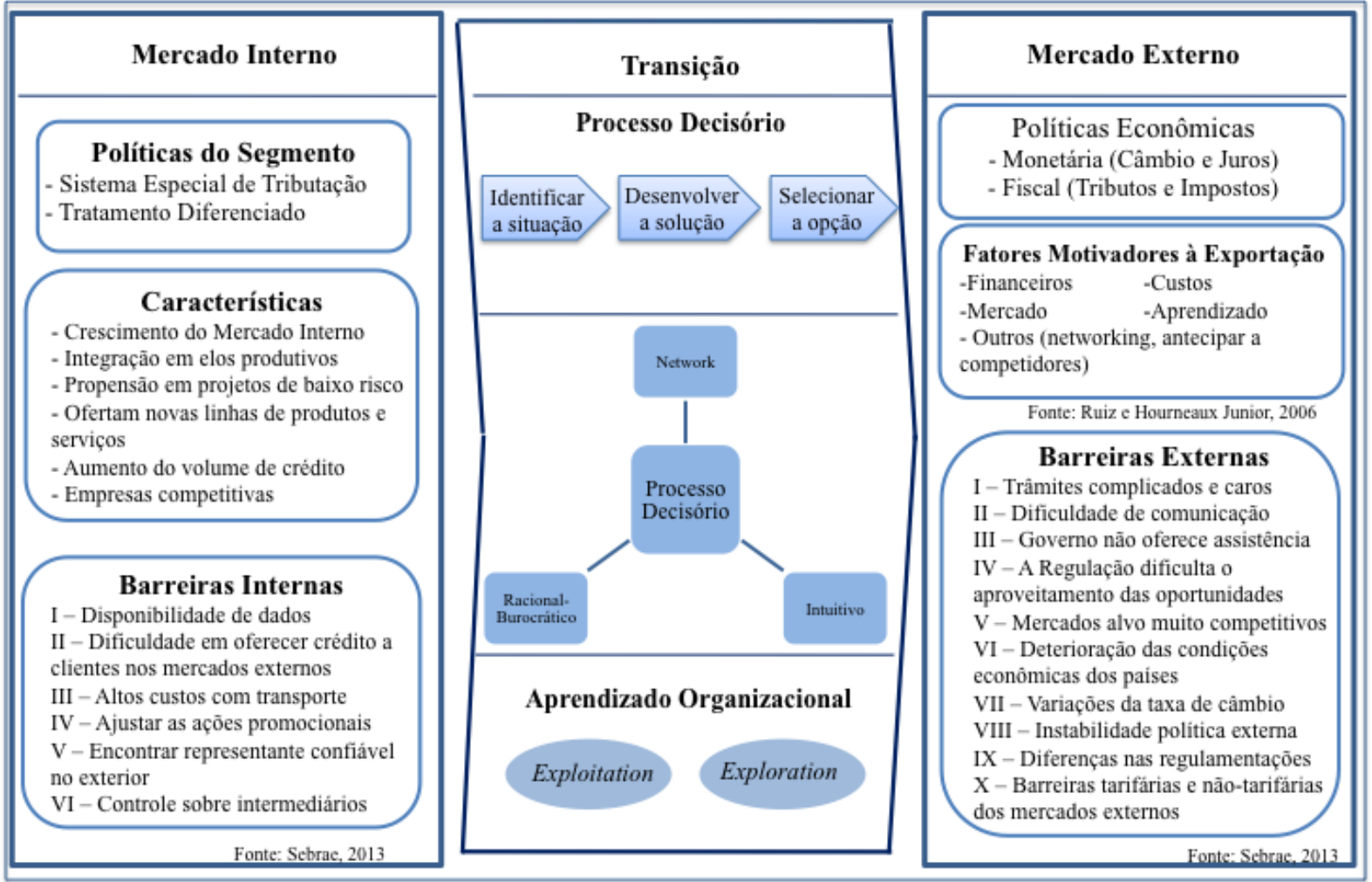

FONTE: Os autores (2016).

A Figura 2 é formada por nove conjuntos de elementos, subdividida em três macro grupos, sendo Mercado Interno, Transição e Mercado Externo, indicando algumas características percebidas em solo nacional. O primeiro conjunto, Política do Segmento, indica dois itens que remetem a elementos inclusos na Lei Geral das MPEs, que além de regulamentar o segmento possui, capítulos dedicados à promoção da competitividade das MPEs. Inclui também algumas características do segmento em que estão inseridas as MPEs que possuam alguma possibilidade de exportação e fatores que dificultam a exportação, tidos como Barreiras Internas (SEBRAE, 2013), a serem enfrentados e que devem ser superados.

O segundo conjunto, intitulado Transição, visa demonstrar a adoção teórica do pensamento estratégico, considerando a relevância de se formular uma estratégia de fato sustentável, bem como sua integral implementação, conectando-a à prática cotidiana da empresa (MINTZBERG; QUINN, 1996). O Processo Decisório poderá estar ancorado em uma das três tipologias identificadas e nos principais fatores que motivam as MPMEs a romperem os limites fronteiriços de sua atuação,

ZICA, R. M. F.; GONÇALVES, C. A.; MARTINS, H. C. Internacionalização de micro, pequenas e médias empresas: uma avaliação sobre o processo decisório estratégico.

Revista de Empreendedorismo e Gestão de Pequenas Empresas, v.5, n.3, 2016. 
seja por meio de aspectos endógenos, de adequação da condução estratégica ou por aspectos mais exógenos, como a identificação e busca de novas oportunidades de mercado.

Para Teece, Pisano e Shuen (1997), as empresas necessitam identificar suas capacidades (dinâmicas), de modo a identificar e redefinir suas competências internas e externas, de modo a estarem aptas às mudanças do ambiente de negócio. Conforme March (1991) e Pardini, Santos e Gonçalves (2000), este aprendizado organizacional ocorre por meio da exploração de novos conhecimentos, envolvendo pesquisa e busca de inovação, de modo a gerar a implantação de processos que agreguem novas competências em médio e longo prazo (exploration). O aprendizado também pode ocorrer por meio da utilização e aprimoramento dos conhecimentos existentes na organização, de modo a buscar a eficiência, otimização de recursos e maiores resultados nem curto prazo (exploitation). Estes elementos são essenciais para o processo decisório do gestor, quando na definição da transição entre o mercado interno e o externo.

O último conjunto, Mercado Externo, indica as Políticas Econômicas adotadas. Aqui, os empreendedores devem acompanhar os sinais emitidos pelo mercado, pois tais indicadores podem representar significativas oscilações nas receitas destas empresas, caso não sejam adotadas medidas profiláticas, como fundos de hedge, contratos bem realizados e seguros. Os Fatores Motivacionais à Exportação apresentam um conjunto de temas onde existem oportunidades de mercado, devendo o empreendedor saber aproveitá-las. É importante também saber enfrentar e superar as Barreiras Externas.

As empresas de menor porte, estando submetidas às idiossincrasias do mercado interno, ao considerarem possibilidades existentes ou a serem desenvolvidas de atuarem no mercado externo, tendem a avaliar o quão factível são estas oportunidades, os fatores que a motivam e, sobretudo, quais serão as implicações decorrentes deste processo decisório. 


\section{Considerações Finais}

As empresas de menor porte assumem relevante papel na economia nacional, tanto sob a ótica de geração de empregos e renda, quanto para a construção do PIB nacional. Todavia, percebe-se a existência de lacuna a ser preenchida no tocante à sua internacionalização. Outra questão proeminente para este trabalho foi a busca pela compreensão de aspectos que motivam ou desmotivam os empresários de micro, pequenos e médios negócios a expandirem suas operações a outros países e como ocorre esta decisão.

De uma maneira geral, percebe-se a existência de grande quantidade de dados e informações sobre exportações no país, oriundo de instituições e órgãos destinados à sua análise, bem como por sua promoção, como o é caso da MDIC, APEX, Sebrae, Funcex, Centrais de Exportação, Fundações, para citar alguns exemplos.

Com as informações coletadas, é possível, na maioria das vezes, estratificar informações sobre as MPMEs, focalizando as especificidades do segmento e formas de atuação. Esses dados e informações são relevantes para que o empreendedor possa mitigar riscos no processo de internacionalização de suas atividades, sejam elas iniciais ou contínuas, dadas as constantes mudanças de cenário existentes em um mundo globalizado.

O tema também merece atenção por parte da academia, pois percebe-se 0 aumento de trabalhos relacionados à internacionalização de negócios de menor porte e a destinação de seminários e seções temáticas específicas para se debater o assunto. Não obstante esta melhoria do quadro científico, percebe-se a necessidade de mais estudos sobre o campo de conhecimento, mormente que analisem os três pilares fundamentais deste trabalho: processo decisório estratégico, internacionalização e micro, pequenas e médias empresas.

No tocante ao ambiente de negócios, a pesquisa realizada pelo Sebrae (2013) evidenciou aspectos que envolvem o segmento das MPEs, merecendo destaque o grau de maturidade dos empreendimentos, tendo em vista que $41,2 \%$ das empresas têm acima de 20 anos de existência. Em 70,6\% destas empresas, os 
atuais empreendedores foram os responsáveis pela fundação do negócio. Pode-se dizer que existe concentração de atividades, pois cerca de dois terços das empresas são do setor industrial. Como destino final das exportações, a pesquisa relevou que as MPEs não se restringem aos países do chamado cone sul, em função das distâncias geográficas ou eventual aproximação psíquica, mas expandem sistematicamente suas operações a países dos demais continentes. A palavra sistematicamente foi corretamente empregada, pois $59,2 \%$ das empresas exportam mais de 4 vezes ao ano, sendo que quase um terço da composição de receitas das MPEs exportadoras provêm de vendas externas.

Com relação à pesquisa de campo, foi possível perceber que os empreendedores entrevistados buscam conciliar aspectos cognitivos, como a intuição, com análises mais técnicas, calcadas em pesquisas, informações e em suas redes de relacionamentos. Como houve maior preponderância para a análise de estudos e pesquisas, em detrimento à intuição, e tomando a Matriz de Polaridade de Decisão como referência, pode-se dizer que os entrevistados se concentram dentro do perfil racional-burocrático, com características mais moderadas, pois tendem a balizar suas decisões por meio de informações disponíveis para a tomada de decisão e por meio de consenso.

Outro ponto relevante para o segmento é o relacionamento com os players de mercado. Este network se mostrou instrumento essencial aos empresários, pois as respostas deram ênfase aos construtos "contatos no exterior" e "possuir demanda de cliente no exterior".

Com base no referencial teórico e nas pesquisas realizadas foi possível perceber as razões que motivam ou desmotivam os empresários de pequenos negócios a expandirem suas operações a outros países e, sobretudo, como ocorre o processo desta decisão, atendendo ao objetivo principal deste trabalho.

Caberia salientar que este trabalho apresenta certas limitações empíricas, pois a pesquisa quantitativa foi realizada com empresas situadas dentro de um único estado, Minas Gerais, e a qualitativa não abrangeu grande volume de respondentes. Como sugestão para trabalhos futuros, pode-se realizar este estudo em outras localidades e regiões do país, de modo a comparar seus resultados, bem como 
aprofundar pesquisas comparativas entre setores de diferentes países para conhecer como ocorre a tomada de decisão nestes ambientes.

Embora não seja possível determinar comportamentos dos empreendedores pela quantidade de respostas, é possível fazer uma indução a respeito, servindo de base para a teorização. Em última instância, espera-se que com este trabalho possam ser extraídas informações relevantes, dados e estatísticas consistentes sobre a internacionalização de pequenos negócios no país, de modo a contribuir para sua expansão, bem como melhorias em seus processos decisórios.

\section{Referências:}

BERNARDES, M. E. B. Estratégias de Aprendizagem em Pequenas Empresas: as learning organizations e o papel do empreendedor. In: ENCONTRO DE ESTUDOS EM ESTRATÉGIAS, 1, 2003, Curitiba. Anais... Curitiba, 2003.

BRITO, R. P.; BRITO, L. A. L. Dynamics of Competition and Survival. BAR, v. 11, n. 1 , art. 4, p. 64-85, 2014.

CASTELLS, M. A Sociedade em Rede. Tradução de: MAJER, R. V. 4. ed. São Paulo: Paz e Terra, 2000.

CHILD, J.; ELBANNA, S.; RODRIGUES, S. B. The Political Aspects of Strategic Decision Making. In: PAUL, C. N.; DAVID, C. W. (Ed.). The Handbook of Decision Making, Chichester: Wiley, 2010.

CYERT, T.; MARCH, J. A Behavioral Theory of the Firm. Prentice Hall, 1963.

D'AVENI, R. A.; DAGNINO, G. B.; SMITH, K. G. The age of Temporary Advantage. Strategic Management Journal, v. 31, n. 13, p. 1.371-1.385, 2010.

DIMAGGIO, P. J.; POWELL, W. W. The Iron Cage Revisited: institutional isomorphism and collective rationality in organizational fields. American Sociological Review, v. 48, n. 2, p. 147-160, 1983.

DRUCKER, P. F. Sociedade Pós Capitalista. São Paulo: Pioneira, 1999.

FILION, L. J. O Planejamento do seu Sistema de Aprendizagem Empresarial: identifique uma visão e avalie seu sistema de relações. Revista de Administração, v. 31, n. 3, p. 63-71, 1991. 
FRANÇA FILHO, G. G.; TEIXEIRA, L. A. A.; SILVA, J. T. M.; REIS NETO, M. T. A Internacionalização nas Pequenas e Médias Empresas Brasileiras: a influência da distância psíquica. Revista da Micro e Pequena Empresa, v. 5, n. 1, p. 3-19, 2011.

GERLETTI, S. Processo Decisório Estratégico na Empresa Industrial de Pequeno Porte: um estudo de caso. 2009. 169 f. Dissertação (Mestrado em Administração). Faculdade de Economia, Administração e Contabilidade, Universidade de São Paulo, São Paulo, 2009.

GIBCUS, P.; VERMEULEN, P. A. M.; RADULOVA, E. The decicion-making entrepreneur: a literature review. In: VERMEULEN, P. A. M.; CURSEU, P. L. (Eds.). Entrepreneurial Strategic Decision Making: a cognitive perspective. Cheltenham: Edward Elgar Publishing, 2008, p. 11-40.

GIDDENS, A. O Mundo na Era da Globalização. Lisboa: Presença, 2000.

GIL, A. C. Métodos e Técnicas de Pesquisa Social. São Paulo: Atlas, 1999.

GOVINDARAJAN, V.; GUPTA, A. K. Dominando os Mercados Globais. In: Financial Times. São Paulo: Makron Books, 2001.

HILAL, A.; HEMAIS, C. A. O Processo de Internacionalização na Ótica da Escola Nórdica: evidências empíricas em empresas brasileiras. RAC, v. 7, n. 1, p. 109-124, 2003.

HITT, M. A.; IRELAND, R. D.; HOSKISSON, R. E. Administração Estratégica. São Paulo: Bookman, 2003.

JULIEN, P. A. Prefácio. In: MACHADO, H. P. V. et al. (org.). Empreendedorismo, Oportunidades e Cultura: seleção de casos no contexto brasileiro. Maringá: Eduem, 2013.

MARCH, J. G. Exploration and Exploitation in Organizational Learning. Organization Science, v. 2, n. 1, p. 71-86, 1991.

MARCONI, M. A.; LAKATOS, E. M. Técnicas de Pesquisa. 5. ed. São Paulo: Atlas, 2002.

MDIC, MINISTÉRIO DO DESENVOLVIMENTO, INDÚSTRIA E COMÉRCIO EXTERIOR. Metodologia Aplicada para a Elaboração da Publicação Exportação Brasileira por Porte de Empresa. Brasília: MDIC, 2015.

MELIN, L. Internationalization as a Strategy Process. Strategic Management Journal, v. 13, n. S2, p. 99-118, 1992.

MINTZBERG, H.; QUINN, J. B. The Strategy Process: concepts, contexts, cases. 3. ed. Upper Saddle River: Pretice Hall, 1996.

ZICA, R. M. F.; GONÇALVES, C. A.; MARTINS, H. C. Internacionalização de micro, pequenas e médias empresas: uma avaliação sobre o processo decisório estratégico.

Revista de Empreendedorismo e Gestão de Pequenas Empresas, v.5, n.3, 2016. 
MINTZBERG, H.; RAISINGHANI, D; THORET, A. The Structure as "Unstructure" Decision Process. Administrative Science Quarterly. v. 21, 1976.

NOORAIE, M. Factors influencing strategic decision-making processes. International Journal of Academic Research in Business and Social Sciences, v. 2, n. 7, 2012.

NUTT, P. Making Decision-Making Research Matter: some issues and remedies. Management Research Review, v. 34, n. 1, p. 5-16, 2011.

OECD, ORGANISATION FOR ECONOMIC CO-OPERATION AND DEVELOPMENT. Promoting Entrepreneurship and Innovative SMEs in a Global Economy: Towards a More Responsible and Inclusive Globalisation. In: OECD CONFERENCE OF MINISTERS RESPONSIBLE FOR SMALL AND MEDIUM-SIZED ENTERPRISES, 2 , 2003, Istambul. Conference... Istambul, 2004.

OLIVEIRA, P. H.; GONÇALVES, C. A.; PAULA, E. A. M. A Visão Baseada em Recursos da Inteligência Competitiva. Revista de Ciências da Administração, v. 15, n. 35, p. 141-151, 2013.

OLIVEIRA, P. T.; NUNES, T.; DESTEFENI, J. M. D. Internacionalização de Empresas Brasileiras: os casos Tigre e Bematech. In: ENANGRAD - ANPAD, 23, 2012, Bento Gonçalves. Anais... Bento Gonçalves, 2012.

PAIVA JUNIOR, F. G.; GUERRA, J. R. F.: Empreendedorismo Internacional: competências empreendedoras para acesso ao mercado externo. In: COLÓQUIO SOBRE EMPREENDEDORISMO E ESTRATÉGIA DE EMPRESAS DE PEQUENO PORTE - 3Es2Ps, 2, 2009, Curitiba. Anais... Curitiba, 2009.

PARDINI, D. J.; SANTOS, R. V.; GONÇALVES, C. A. A dinâmica da aprendizagem intra e Inter-organizacional: perspectivas em estratégias cooperativas e competitivas utilizando as tipologias de exploration e exploitation. Revista BNDES Setorial, n. 12, p. 195-204, 2000.

PORTER, M. What is Strategy? Harvard Business Review, v. 74, n. 6, p. 61-78, 1996.

PUGA, F. P. Experiências de Apoio às Micro, Pequenas e Médias Empresas nos Estados Unidos, Itália e Taiwan. BNDES, 2000.

RICHARDSON, R. J. Pesquisa social: métodos e técnicas. São Paulo: Atlas, 1989.

RODRIGUES, S. B. Processo Decisório em Universidades: teoria III. Revista de Administração Pública, v. 19, n.4, p. 60-75, 1985.

RODRIGUES, S. B.; CHILD, J. Building Social Capital for Internationalization. RAC, v. 16, n. 1, art. 2, p. 23-38, 2012.

ZICA, R. M. F.; GONÇALVES, C. A.; MARTINS, H. C. Internacionalização de micro, pequenas e médias empresas: uma avaliação sobre o processo decisório estratégico.

Revista de Empreendedorismo e Gestão de Pequenas Empresas, v.5, n.3, 2016. 
RUIZ, F. M.; HOURNEAUX JUNIOR, F. Exportações Brasileiras e Micro e Pequenas Empresas. In: WORKSHOP SOBRE INTERNACIONALIZAÇÃO DE EMPRESAS FEA/USP, 2006, São Paulo. Workshop... São Paulo, 2006.

SEBRAE. As Micro e Pequenas Empresas na Exportação Brasileira. Brasil: 1998-2011. Brasília: Sebrae, 2012.

SEBRAE. Participação das Micro e Pequenas Empresas na Economia Brasileira. Brasília: Sebrae, 2014.

SEBRAE. Pesquisa de Internacionalização: micro, pequenas e médias empresas. Minas Gerais: Sebrae, 2013.

SILBER, S. D. Mudanças Estruturais na Economia Brasileira (1988 - 2002): Abertura, Estabilização e Crescimento. Universidade de São Paulo, São Paulo: 2006.

SIMON, H. A. Administrative Behavior: a study of decision-making processes in administrative organization. 3. ed. New York, 1976.

SIRMON, D. G. et al. The Dynamic Interplay of Capability Strengths and Weaknesses: investigating the bases of temporary competitive advantage. Strategic Management Journal, v. 31, n. 13, p. 1.386-1.409, 2010.

TEECE, D. J.; PISANO, G; SHUEN, A. Dynamic Capabilities and Strategic Management. Strategic Management Journal, v. 18, n. 7, p. 509-533, 1997.

TRIVIÑOS, A. N. S. Introdução à pesquisa em ciências sociais: a pesquisa qualitativa em educação. São Paulo: Editora Atlas, 1987. 